\title{
Tutoria das Gurias: Uma ação de acompanhamento de alunas ingressantes em cursos de Computação
}

\author{
Andréa S. Bordin, Alice F. Finger, Letícia Gindri, Aline V. de Mello \\ ${ }^{1}$ Universidade Federal do Pampa (UNIPAMPA) \\ Av. Tiaraju, 810 - Ibirapuitã, Alegrete - RS, 97546-550 \\ \{andreabordin, alicefinger, leticiagindri, alinemello\}@unipampa.edu.br
}

\begin{abstract}
The percentage of female graduates in Computer Science courses in Brazil has been decreasing over the years. Thus, actions that promote permanency of female students are necessary. This paper presents a mentoring initiative of incoming female students carried by female professors, that took place in the first semester of 2019. The analysis of the perception of those involved in this action shows that personal contact between students and professors and the students engagement in research, teaching and extension projects can stimulate the continuity in the undergraduate programs.
\end{abstract}

Resumo. O percentual de egressas em cursos da área de Computação no Brasil vem diminuindo ao longo dos anos. Assim, ações que estimulem a permanência de discentes do sexo feminino são necessárias. Este artigo apresenta uma ação de tutoria de discentes ingressantes conduzidas por docentes do sexo feminino, realizada no primeiro semestre letivo de 2019. A análise da percepção das envolvidas na ação mostra que o contato pessoal entre tutoras e discentes e o engajamento das discentes em projetos de pesquisa, ensino e extensão podem estimular a permanência nos cursos.

\section{Introdução}

De acordo com os dados da Sociedade Brasileira de Computação (SBC) [SBC 2018] o percentual de mulheres concluintes vem decrescendo entre os anos 2001 e 2017, com $31,8 \%$ e $15,4 \%$, respectivamente. Dentre as principais causas de evasão de mulheres na área da Computação é possível citar a associação socialmente construída entre tecnologia e masculinidade [Louzada et al. 2019]. Além disso, uma pesquisa realizada com professores e estudantes de cursos da área da Computação concluiu que comentários ruins, machismo e a desvalorização do trabalho das alunas, não somente por parte dos alunos mas também dos professores, impactam diretamente na autoestima e podem contribuir para a evasão de mulheres [Mello et al. 2019].

Essa situação tem levado à criação de ações para incentivar a participação e permanência feminina na área. No Brasil existem o programa Meninas Digitais, promovido pela Sociedade Brasileira de Computação, o projeto Gurias na Computação [Ferrão et al. 2017], dentre diversos outros. Ações neste escopo costumam focar tanto em alunas da educação básica, estimulando o interesse e o ingresso em cursos da área, quanto no engajamento das alunas graduandas, evitando a evasão.

Dentre essas ações que visam manter as alunas em seus cursos, os programas de acompanhamento de alunos ingressantes, chamados de tutoria ou mentoring, são uma 
possibilidade já adotada por muitas instituições. Em alguns casos a tutoria é feita por alunos que estão em semestres mais avançados [Franzoia et al. 2019, Scaico et al. 2012], em outros os docentes assumem o papel de tutores [Leite et al. 2019, Peres et al. 2014].

Nos cursos de Ciência da Computação (CC) e Engenharia de Software (ES) da Universidade Federal do Pampa, Campus Alegrete, foi conduzido um programa de acompanhamento de alunas ingressantes, denominado Tutoria das Gurias, no qual as docentes do curso acompanharam grupos de alunas durante o primeiro semestre letivo de 2019. Este artigo objetiva apresentar a metodologia do programa de tutoria e analisar os resultados na percepção das discentes e das docentes, o que pode ajudar outras instituições no planejamento de ações similares.

O artigo está organizado da seguinte maneira: na Seção 2 são apresentados os trabalhos relacionados às ações de tutoria em cursos de Computação. Na Seção 3 é apresentada a metodologia da ação de tutoria. O perfil das alunas ingressantes e a percepção de discentes e docentes acerca dessa ação são apresentados e discutidos na Seção 4. Por fim, na Seção 5 são apresentadas as considerações finais.

\section{Trabalhos Relacionados}

Diversos estudos relatam experiências com programas de tutoria em cursos de Computação. Em relação à condução da tutoria propriamente dita, observou-se as seguintes formas: docentes e discentes veteranos atuam como tutores; somente docentes ou somente discentes. Em relação ao público-alvo, observou-se: ações que focam em ingressantes de maneira geral; ações que focam em ingressantes do sexo feminino; e, por fim, ações que abrangem todos os alunos durante todo o curso.

Em relação ao tempo de duração, existem as que duram apenas um semestre, outras que duram alguns semestres e as que duram toda a graduação. Por fim, observou-se também: ações que focam na tutoria de alguma área específica e ações que visam auxiliar os alunos em um espectro mais amplo, como orientações e auxílios diversos ao longo da trajetória acadêmica. A Tabela 1 apresenta um panorama dos programas de tutoria em 4 universidades públicas, os quais são descritos a seguir.

Tabela 1. Abordagens dos trabalhos relacionados

\begin{tabular}{lcccccc} 
Instituição & Tutor & \multicolumn{1}{c}{ Público-alvo } & \multicolumn{1}{c}{ Duração } & Abrangência & Referência \\
\hline $\begin{array}{l}\text { Universidade de São } \\
\text { Paulo (USP) }\end{array}$ & Docente & Todos os discentes & Semestres iniciais & Ampla & [USP 2017] \\
\hline $\begin{array}{l}\text { Universidade Federal de } \\
\text { Goiás (UFG) }\end{array}$ & Docente & Todos os discentes & Todo o curso & Ampla & [de Castro et al. 2007] \\
\hline $\begin{array}{l}\text { Universidade do Estado } \\
\text { do Amazonas (UEA) }\end{array}$ & Discente & $\begin{array}{l}\text { Discentes do sexo } \\
\text { feminino }\end{array}$ & Um semestre & Restrita & [Franzoia et al. 2019] \\
\hline $\begin{array}{l}\text { Universidade Federal da } \\
\text { Paraíba (UFPB) }\end{array}$ & Discente & Todos os discentes & Um semestre & Restrita & [Scaico et al. 2012] \\
\hline
\end{tabular}

A USP possui um programa de apoio aos alunos do curso de Ciência da Computação com enfoque mais amplo, oferecendo auxílio em situações diversas a respeito da vida acadêmica dos discentes. O programa está apresentado no projeto pedagógico do curso, não sendo possível encontrar dados sobre benefícios e dificuldades encontradas [USP 2017]. 
O foco do programa de apoio aos alunos dos cursos de Ciência da Computação e Engenharia Elétrica da UFG também é amplo. Sob o ponto de vista dos alunos, destacamse como benefícios deste programa o acesso às informações sobre a vida acadêmica e áreas de atuação profissional, conhecimento dos projetos de pesquisa dos professores tutores, dedicação em se manter no fluxo sugerido pelo curso. Já sob o ponto de vista dos docentes, destacam-se o maior envolvimento com serviços institucionais oferecidos aos alunos e estreitamento das relações com o corpo discente. Os docentes destacam como dificuldade encontrada a comunicação e a adesão dos alunos ao programa [de Castro et al. 2007].

Por outro lado, os programas de tutoria da UEA [Franzoia et al. 2019] e da UFPB [Scaico et al. 2012] possuem foco mais restrito, dando prioridade para a tutoria em programação. Em relação ao primeiro, destaca-se o foco específico em discentes do sexo feminino. Pontos positivos deste tipo de tutoria são o maior engajamento nas aulas, uma expressiva melhora no desempenho no componente curricular e uma redução na taxa evasão do componente.

Em vista do que foi descrito, é notável que ações e projetos que envolvam tutoria para discentes de cursos de Computação apresentam um retorno positivo tanto por parte dos docentes quanto dos discentes. Porém, existe uma demanda de ações voltadas especificamente para as discentes, uma vez que esse gênero está cada vez menos presente nos cursos. O diferencial do presente trabalho está no desenvolvimento de uma ação voltada às discentes ingressantes nos cursos de CC e ES conduzida pelas docentes dos cursos.

\section{Metodologia da Ação Tutoria das Gurias}

A ação de acompanhamento de alunas ingressantes nos Cursos de Ciência da Computação e Engenharia de Software foi desenvolvida no primeiro semestre de 2019, dentro do escopo do projeto de extensão Gurias na Computação [Ferrão et al. 2017]. Ao oferecer às alunas um serviço de apoio e aconselhamento durante o seu primeiro semestre, a ação objetivou incentivar a permanência no curso, ou seja, evitar a evasão.

A ação foi operacionalizada por cinco (5) docentes do sexo feminino, que já atuavam no projeto de extensão, através das seguintes etapas:

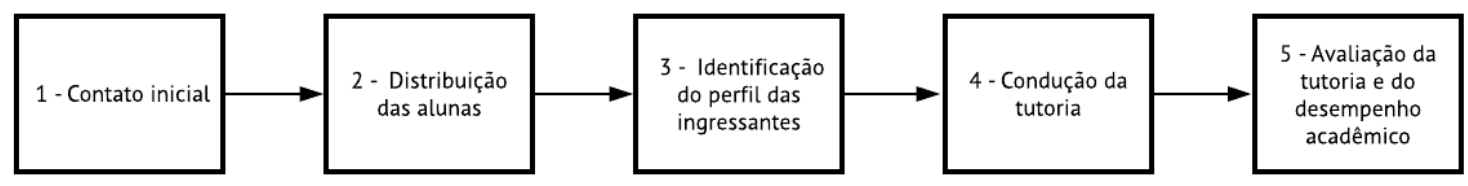

Figura 1. Metodologia da ação

1. Contato inicial: envio de e-mail às alunas, apresentando o projeto de extensão Gurias na Computação e o objetivo da ação Tutoria das Gurias. Adicionalmente, as alunas foram convidadas para um primeiro encontro geral, visando a apresentação das tutoras e das tutoradas, bem como os benefícios da tutoria.

2. Distribuição das alunas: um grupo de 3 ou 4 alunas foi atribuído a cada docente. Os critérios de atribuição foram elegidos pelas docentes. Das 5 docentes participantes da ação, 3 ministraram componentes curriculares do primeiro semestre. 
Dessas, duas preferiram tutorear alunas matriculadas em componentes curriculares ministrados por elas,enquanto outra preferiu tutorear alunas que não estivessem cursando nenhum de seus componentes curriculares. Dadas essas condições, a distribuição foi feita de maneira aleatória, tentando contemplar as preferências.

3. Identificação do perfil das ingressantes: aplicação de um questionário ${ }^{1}(\mathrm{Q} 1)$ para as alunas ingressantes com o objetivo de conhecer o perfil socioeconômico, demográfico e comportamental das mesmas e, assim, planejar as ações de acompanhamento e identificar possíveis causas de evasão.

4. Condução da tutoria: cada tutora teve autonomia para definir como seriam desenvolvidas as atividades. Foram propostas atividades como encontros presenciais em um café fora da universidade, encontros na sala da tutora, encontros em sala de reunião na universidade, criação de grupos de comunicação em redes sociais, etc. A Tabela 2 apresenta como foi realizado o primeiro contato com as tutoradas, bem como descreve a forma de condução da tutoria por cada uma das docentes, além de identificar se a tutora ministrou aulas para as suas respectivas tutoradas.

5. Avaliação da tutoria e do desempenho acadêmico: um questionário de avaliação $^{2}(\mathrm{Q} 2)$ foi aplicado às alunas no início do segundo semestre, com o objetivo de avaliar a percepção em relação à dificuldade de aprendizagem nos componentes curriculares cursados no primeiro semestre, a participação em projetos de ensino, pesquisa e extensão e sua possível relação com a permanência no curso e, por fim, avaliar a ação de tutoria em si. As tutoras também avaliaram a ação, relatando os pontos positivos e o que deve ser aprimorado.

Tabela 2. Forma de condução da tutoria

\begin{tabular}{|c|c|c|}
\hline Docentes & Como foi conduzido & Ministrou \\
\hline Docente 1 & $\begin{array}{l}\text { Fez contato presencial em sala de aula. Observou que as tutoradas tinham dificuldades em } \\
\text { seu componente curricular e marcou encontros semanais em sua sala, nos quais sanava as } \\
\text { dúvidas sobre o conteúdo, passava atividades e corrigia. }\end{array}$ & Sim \\
\hline Docente 2 & $\begin{array}{l}\text { Fez um convite por e-mail para um encontro inicial e também as convidou para um en- } \\
\text { contro em uma cafeteria. Teve encontro presencial em sua sala. }\end{array}$ & Não \\
\hline Docente 3 & $\begin{array}{l}\text { Criou um grupo em um aplicativo de mensagens para que pudessem ter um contato mais } \\
\text { rápido e convites pudessem ser feitos para participação em ações de extensão, eventos } \\
\text { culturais e projetos de pesquisa. Realizou encontros presenciais em uma cafeteria. }\end{array}$ & Sim \\
\hline Docente 4 & $\begin{array}{l}\text { Fez contato por e-mail para combinar os encontros com as tutoradas. Propôs encontros } \\
\text { na sua sala. }\end{array}$ & Não \\
\hline Docente 5 & $\begin{array}{l}\text { Fez um convite por e-mail para uma conversa inicial. Realizou um encontro presencial } \\
\text { em uma cafeteria. }\end{array}$ & Não \\
\hline
\end{tabular}

\section{Resultados}

Nesta seção são apresentados e discutidos os resultados da ação, começando pela síntese dos dados quantitativos de envolvimento das discentes desde a matricula até a conclusão da ação, seguido da análise do perfil das alunas ingressantes e, por fim, da análise da percepção das discentes e das docentes acerca da ação.

\footnotetext{
${ }^{1} \mathrm{O}$ questionário para identificação do perfil pode ser consultado através do link: bit.ly/q1Tutoria

${ }^{2} \mathrm{O}$ questionário de avaliação pode ser consultado através do link: bit.ly/q2Tutoria
} 
A Tabela 3 traz uma síntese dos dados quantitativos, agrupados por tutora, referentes às discentes envolvidas na ação de tutoria. É possível perceber que no início do semestre letivo 17 discentes estavam matriculadas, 10 responderam ao Q1 e 7 participaram efetivamente da ação. Ainda, 4 discentes ficaram infrequentes ou evadiram durante o semestre. Observa-se que o número de respondentes do Q2 foi maior que o número de participantes da ação porque mesmo aquelas que não participaram responderam o Q2.

\begin{tabular}{cccccc}
$\begin{array}{c}\text { Tabela 3. Dados quantitativos sobre o envolvimento das discentes na tutoria } \\
\text { Tutora }\end{array}$ & Matriculadas & Resp. Q1 & Participaram & Infreq/evadidas & \begin{tabular}{c} 
Resp. Q2 \\
\hline Docente 1
\end{tabular} \\
\hline & 4 & 3 & 2 & 0 & 3 \\
Docente 2 & 3 & 2 & 1 & 2 & 3 \\
Docente 3 & 3 & 3 & 2 & 0 & 2 \\
Docente 4 & 3 & 1 & 0 & 1 & 1 \\
Docente 5 & 4 & 2 & 2 & 1 & 1 \\
\hline Total & 17 & 10 & 7 & 4 & 10 \\
\hline
\end{tabular}

Em relação às ingressantes que ficaram infrequentes ou evadiram, foi solicitado o apoio do NuDE (Núcleo de Desenvolvimento Educacional), que entrou em contato com as discentes e buscou entender os motivos da infrequência, dentre os quais destacam-se problemas na família e dificuldade de deslocamento até a universidade. Salienta-se que os dois cursos, CC e ES, ocorrem no turno noturno.

\subsection{Perfil das alunas ingressantes}

No inicio do semestre letivo de 2019 foi aplicado um questionário às discentes ingressantes nos cursos de ES e CC com o objetivo de coletar dados que possibilitem o planejamento das ações da tutoria, bem como um entendimento futuro em relação as causas de possíveis evasões. Foram coletados dados referentes ao perfil demográfico, socioeconômico, de saúde e comportamental das discentes.

No curso de CC ingressaram 9 discentes do sexo feminino e no curso de ES 8, totalizando 17 discentes do sexo feminino (17\% dos ingressantes). Desse número, 10 discentes responderam a esse primeiro questionário (Q1). Os resultados desse instrumento possibilitaram estabelecer o perfil das discentes, do qual destacam-se:

- Predominam discentes naturais da cidade em que a instituição se situa ou região (9), com idade entre 17 e 19 anos (7) e que não trabalham (10);

- A maioria reside com os pais (6), sendo que a grande maioria tem renda familiar per capita de até 1,5 salários mínimos (9);

- A maioria possui acesso a notebook e smartphone, internet em casa, tem conhecimento prévio em informática e não tem experiência de trabalho na área (9);

- A maioria tem qualidade de sono boa a muito boa (6), a grande maioria acha importante ser fisicamente ativa (7), embora a metade não esteja satisfeita com o peso atual (5) e poucas se considerem fisicamente ativas (3). A grande maioria raramente consome bebidas alcoólicas e não fuma (9). Dentre as queixas de saúde mais frequentes, destacam-se o cansaço mental (6) e o nervosismo constante (5);

- Para a metade das discentes, os cursos de CC e ES não foram a primeira opção. No entanto, os escolheram por gostarem da área e por acharem que oferecem mais oportunidades de trabalho. Todas se imaginam trabalhando na área, se interessam por programação e pretendem concluir o curso; 
- A grande maioria já imaginava que haveria poucas meninas no curso (8) e afirmaram que isso representava um problema (7). A metade disse não conhecer mulheres que são referência na área da Computação.

$\mathrm{Na}$ análise do perfil das ingressantes percebeu-se que, apesar de serem conscientes de que haveria poucas meninas nos cursos, as discentes afirmaram que isso representava um problema. Compreende-se que as discentes podem se sentir deslocadas, não se enxergando como pertencentes àquele espaço. Outro ponto a destacar é que podem se sentir desconfortáveis com comentários tanto de colegas quanto de professores [Mello et al. 2019]. Além disso, o desconhecimento de mulheres consideradas referências na Computação confirma a conhecida falta de representatividade na área. Acredita-se que isso impacte na escolha de cursos dessa área, já que muitas não imaginam que a Computação possa ser estudada e exercida por mulheres.

\subsection{Percepção das discentes}

Concluído o semestre de tutoria, foi aplicado um questionário (Q2) com o intuito de coletar informações em relação às dificuldades enfrentadas nos componentes curriculares e na vivência universitária; e a relação entre a participação em projetos de ensino, pesquisa e extensão e a permanência no curso. Por fim, a percepção sobre a condução da tutoria e a sua efetividade foram avaliadas. Dez alunas (7 de CC e 3 de ES) responderam o instrumento de avaliação da ação de tutoria no início do segundo semestre, dessas, 2 se declararam infrequentes.

Em relação ao nível de dificuldade nos componentes curriculares do primeiro semestre, observa-se na Figura 2 que Algoritmos e Programação foi um componente apontado como fácil a normal pela maioria das discentes, contrariando o conhecido senso de dificuldade relatado por alunos da área. Uma possível explicação é o fato de todas as discentes terem informado se interessar por programação no Q1. O componente mais difícil para as discentes de ES foi Lógica Matemática, que por sua vez foi considerado fácil ou normal pela maioria das discentes de CC. Entende-se que essa facilidade possa estar relacionada ao fato da docente - que ministrou o componente em ambos os cursos - ter sido tutora das discentes de CC e, consequentemente, ter dado mais apoio extraclasse. Como fatores dificultadores, destacam-se a natureza do conteúdo e a didática do professor. Porém, a didática também aparece como o principal fator facilitador para os componentes considerados fáceis.

No que tange às dificuldades gerais enfrentadas pelas discentes no primeiro semestre estão as exibidas na Figura 3. Pode-se observar que a dificuldade em relação ao desempenho acadêmico, provavelmente relacionada com os fatores dificultadores anteriormente apontados, está presente na maioria das respostas. Ainda nessa temática, as discentes relataram que costumavam, com maior frequência, procurar colegas de sala e internet quando em dificuldades ou dúvidas. Opções como a tutora, o monitor, a coordenação do curso e os familiares estavam disponíveis como resposta no questionário, mas não foram selecionadas por nenhuma discente. A justificativa para a não procura pela tutora pode estar associada à timidez e falta de proximidade com a tutora, como mencionado pelas discentes.

A participação em projetos de pesquisa, ensino e extensão também foi explorada, na perspectiva de que a participação em tais projetos pode ajudar na permanência no 


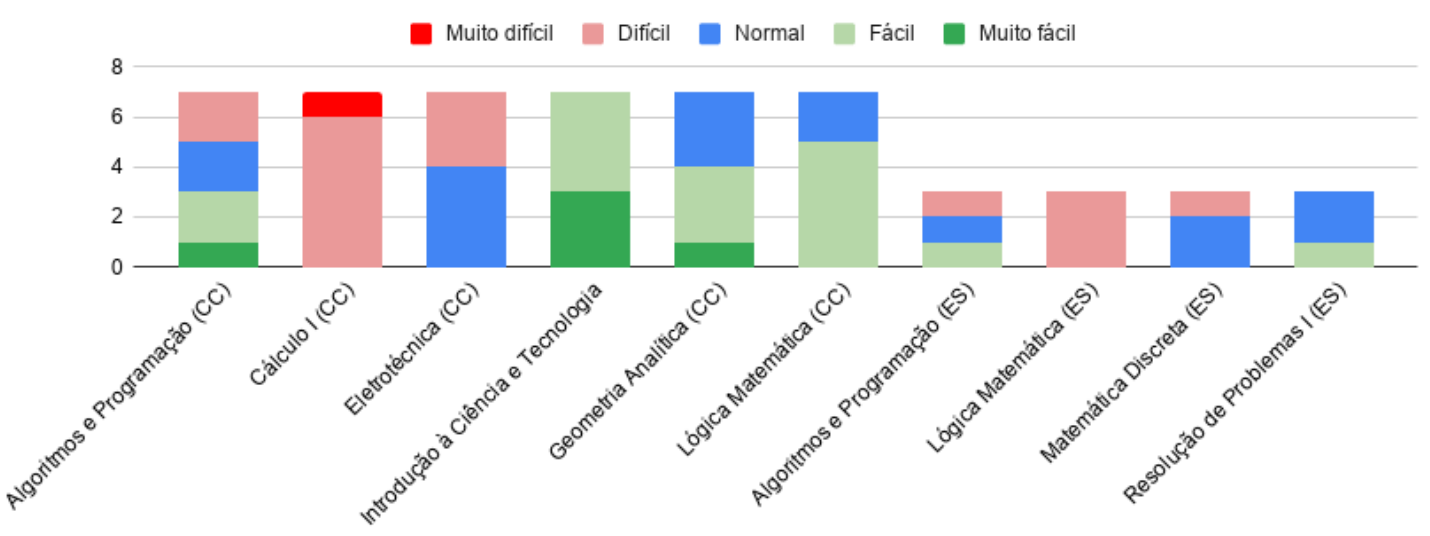

Figura 2. Nível de dificuldade nos componentes curriculares das discentes de CC e ES

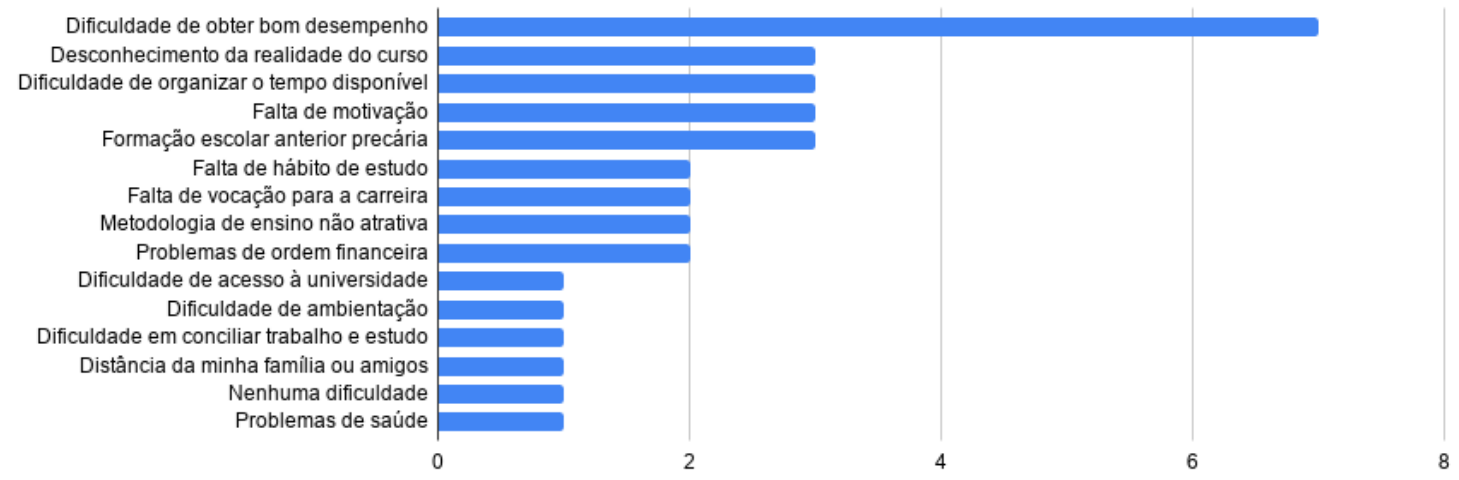

Figura 3. Dificuldades gerais das discentes tutoradas

curso. Das 10 discentes, 4 participaram em projetos e afirmaram que isso as ajudou a permanecerem nos cursos. Os seguintes trechos foram extraídos das respostas das discentes: "A pesquisa me ajudou a ver a quantidade de oportunidades que tenho"; "Ajudou a me manter ligada ao curso"; "Descobri um lado magnífico da educação"; "Fiz novas amizades e aprendi novas coisas".

A ação de tutoria em si foi avaliada em relação à participação em atividades, suficiência de número de encontros, qualidade da interação com a tutora e efetividade da tutoria. Para as que responderam ao Q2 e participaram das atividades (6), metade achou que o número de encontros foi suficiente e a outra metade considerou que foram poucos encontros. A interação com a docente tutora foi considerada boa a muito boa para 5 discentes e indiferente para 1. Em relação à efetividade, buscou-se conhecer os impactos que a ação de tutoria provocou nas discentes. Foi percebido que a tutoria impactou as discentes em pelo menos um dos três aspectos: ajudando a compreender o curso e/ou a universidade (4); a compreender o conteúdo de um ou mais componentes curriculares (3); e a criar laços com colegas e/ou professores (2). Destaca-se que as discentes tinham a opção de escolher nenhum impacto. 
Quando questionadas se a ação de tutoria colaborou para a permanência no curso, 4 tenderam a concordar, 2 discordaram e 1 foi indiferente. Cabe salientar que todas as discentes relataram que gostariam que a ação continuasse no próximo ano. Por fim, no espaço destinado a inserção de sugestões e críticas para que a ação de tutoria possa ser aprimorada, duas discentes sugeriram aumentar o número de encontros.

\subsection{Percepção das docentes}

Assim como aconteceu com as discentes, foi realizado um questionamento às tutoras com o objetivo de que cada uma descrevesse a sua percepção sobre o pontos positivos e negativos na condução da tutoria à luz dos mesmos elementos questionados às discentes. A Tabela 4 resume a percepção das docentes.

\begin{tabular}{l|l}
\multicolumn{2}{c}{ Tabela 4. Percepção das docentes sobre o projeto de tutoria } \\
Pontos positivos & \multicolumn{1}{c}{ Pontos negativos } \\
\hline $\begin{array}{l}\text { - Ministrar componente curricular para as tutora- } \\
\text { das. }\end{array}$ & $\begin{array}{l}\text { - Pouca adesão das tutoradas aos encontros pro- } \\
\text { postos pelas tutorias. }\end{array}$ \\
- Adesão de tutoradas em projeto de ensino, pes- & - Falta de auxílio em componentes curriculares \\
quisa e extensão. & não ministrados pelas docentes tutoras. \\
- Encontros extraclasse para auxilio em compo- & - Quase nenhuma adesão ao primeiro encontro ge- \\
nentes curriculares. & ral entre as alunas ingressantes e as docentes. \\
- Orientação de matrícula do segundo semestre. & - Contato inicial por e-mail. \\
- Encontros sociais fora do ambiente universitário. & \\
\hline
\end{tabular}

As docentes entendem que o e-mail pode não ser a melhor forma de comunicação, visto que a maioria das ingressantes está acostumada a interagir através de outras mídias sociais. Inclusive, a utilização do e-mail como ferramenta para o contato inicial com as discentes ingressantes pode estar relacionado a um número menor de respostas ao questionário inicial (Q1) em relação ao número total de ingressantes. Além disso, a entrada na universidade é um momento no qual os alunos tem que lidar com um excesso de demandas e leva um tempo para conseguirem se organizar e utilizar o e-mail como uma forma de comunicação dentro desse novo ambiente.

Em relação à pouca adesão aos encontros presenciais, evidenciado pela diferença entre a quantidade de discentes que responderam o Q1 e as que participaram efetivamente da ação de tutoria, como mostra a Tabela 3, destacam-se algumas prováveis causas: timidez, falta de compreensão dos benefícios da tutoria na sua vida acadêmica e a não participação do primeiro encontro geral, o qual propiciaria que todas as envolvidas se conhecessem pessoalmente.

Ministrar componentes curriculares para as tutoradas foi elencado como um ponto positivo, tal fato pode ser observado nas Tabelas 2 e 3 , onde o número de participantes na tutoria foi maior nos casos em que as tutoras foram professoras das suas tutoradas. Ainda, essa relação professora e tutora permitiu um entendimento melhor de componentes curriculares, como foi destacado no Q2 por algumas discentes. Essa percepção vai ao encontro das respostas dadas pelas discentes que não participaram em nenhuma das atividades propostas pelas tutoras, no Q2: "vergonha de procurar a tutora"e "não conhecer e não ter aula com a tutora".

Por fim, as docentes entendem que o envolvimento das discentes em projetos de ensino, pesquisa e extensão a partir do seu ingresso na universidade influenciou positiva- 
mente na frequência e permanência de algumas delas no curso, o que é sustentado pelas discentes que participaram de projetos e relataram que isso as estimulou de alguma forma.

\section{Considerações Finais}

Este artigo apresentou a metodologia de uma ação de acompanhamento de discentes do sexo feminino, ingressantes em dois cursos da área de Computação, assim como a percepção das discentes e docentes em relação a essa experiência. Quando comparada a alguns programas de tutoria na área de Computação existentes em universidades brasileiras, pode-se afirmar que nenhum deles possui as características apresentadas na ação relatada neste artigo, a qual tem foco exclusivamente em discentes do sexo feminino, foi conduzida também por docentes do sexo feminino e teve uma abrangência geral, para além do acompanhamento em componentes curriculares específicos.

A análise das percepções docentes e discentes conduziu a algumas recomendações de melhorias na metodologia da ação. Em relação a forma de abordagem inicial das discentes, recomenda-se que este primeiro contato seja feito por meios menos formais, como telefone ou serviços de mensagens instantâneas, no qual também seja informada a importância do e-mail como ferramenta de comunicação na academia.

Quanto ao questionário que visa conhecer o perfil das ingressantes, orienta-se que o instrumento não seja subutilizado e sirva para delinear ações de condução da tutoria, como por exemplo, orientações sobre auxílios à permanência, a dificuldades pedagógicas e psicológicas e, adicionalmente, sirva como instrumento de análise de dados sobre os motivos da evasão. Em relação ao problema de representatividade das alunas, identificado nesse questionário, sugere-se que este tema seja trabalhado nas ações de condução da tutoria, bem como em componentes curriculares introdutórios. A realização de palestras nas quais sejam apresentadas mulheres de destaque na área, rodas de conversa com exalunas que já estão bem colocadas no mercado de trabalho, são alguns exemplos de ações.

Para mitigar o problema da baixa adesão à ação, sugere-se conduzir a tutoria em duplas de docentes, permitindo que as tutoradas sejam alunas de pelo menos uma de suas tutoras, uma vez que nem todas as docentes ministram componentes curriculares do primeiro semestre. Além disso, recomenda-se a criação de um grupo com todas as discentes e docentes, incluindo também a presença do NuDE, em aplicativo de mensagens instantâneas, no qual poderiam ser realizadas enquetes regulares, de modo que as dificuldades enfrentadas possam ser compartilhadas. A participação em projetos de ensino, pesquisa e extensão deve ser mais estimulada como uma forma de engajamento e permanência no curso.

A análise dos componentes curriculares considerados mais difíceis, tendo a didática dos professores como o principal motivo, pode levar a ações como a alocação estratégica de professores com perfil mais adequado a alunos ingressantes, assim como a criação de projetos de tutoria envolvendo alunos veteranos.

Por fim, a ação permitiu conhecer as alunas, quais os motivos que as trouxeram para o curso, quais as dificuldades encontradas e isso impacta tanto no acolhimento quanto na elaboração de estratégias para prevenir a evasão. Como trabalhos futuros, pretende-se aprimorar a ação de tutoria com as recomendações apresentadas e transformá-la em um projeto de ensino com foco primeiramente nas alunas ingressantes e, posteriormente, em todos os ingressantes e docentes dos cursos de Computação da UNIPAMPA. 


\section{Referências}

de Castro, R. N. A., de J. Ribeiro, C., Nogueira, R. G., Marra, E. G., Matias, L., de Oliveira, M. A. A., and Gonçalves, M. A. B. (2007). Implementação do programa de tutoria nos cursos de Engenharia Elétrica e Engenharia da Computação da Universidade Federal de Goiás. In Anais do XXXV Congresso Brasileiro de Educação em Engenharia.

Ferrão, I., de Mello, A., and Melo, A. (2017). Gurias na computação: fortalecendo e incentivando a participação feminina no ensino superior. In Anais do XI Women in Information Technology, pages 1200-1203, Porto Alegre, RS, Brasil. SBC.

Franzoia, F., Pires, F., and Pessoa, M. (2019). Mentorando Meninas Iniciantes em Programação: Um Estudo de Caso. In Anais do XIII Women in Information Technology, pages 199-203. SBC.

Leite, F., Cardoso, G., Costa, Y., Estrela, I., Pinto, A., Pereira, E., Júnior, G. B., and Rivero, L. (2019). Educação Tutorial em Computação: Uma Análise Retrospectiva das Atividades Realizadas para a Formação Pessoal e Profissional de Cientistas da Computação. In Anais do XXVII Workshop sobre Educação em Computação, pages 101-110. SBC.

Louzada, N., Santana, T., Assis, I., Braga, R., and Braga, A. (2019). Agindo sobre a diferença: atividades de empoderamento feminino em prol da permanência de mulheres em cursos de Tecnologia da Informação. In Anais do XIII Women in Information Technology, pages 69-78. SBC.

Mello, A., Melo, A., and Ferrão, I. (2019). Uma análise sobre questões de gênero nos cursos de Computação do municipio de Alegrete/RS. In Anais do XIII Women in Information Technology, pages 61-68. SBC.

Peres, S., Boscarioli, C., Ferrari, A., Costa, C., Alves, C., de Salles, C., Bruscatto, G., Silva, G., da Silva, L., de Souza, L. F., Teixeira, M., Delmondes, P., and Wagner, P. (2014). O programa de educação tutorial no contexto da graduação em computação: Perfis, percepções e reflexões. In Anais do XXII Workshop sobre Educação em Computação, pages 249-258, Porto Alegre, RS, Brasil. SBC.

SBC (2018). Educação superior em computação Estatísticas - 2017. Sociedade Brasileira de Computação. Disponível em: https://www.sbc.org.br/documentosda-sbc/summary/133-estatisticas/1200-pdf-png-educacao-superior-em-computacaoestatisticas-2017. Acesso em: 28 fev. 2020.

Scaico, P., Duarte, A. C., Alves, G. M. T., Maia, M., de Oliveira, F. M., Neto, S. V. M., et al. (2012). Relato de um modelo de tutoria para programação baseado em experiências com ingressantes de um curso de Licenciatura em Computação. In Anais dos Workshops do XX Congresso da Sociedade Brasileira de Computação.

USP (2017). Universidade Federal de São Paulo. Projeto Político-Pedagógico do Curso de Bacharelado em Ciências de Computação. São Carlos, SP, 2017. Disponível em: https://www.icmc.usp.br/graduacao/ciencias-de-computacao-bacharelado. Acesso em: 28 fev. 2020. 